\title{
ASPECTOS BIOQUÍMICOS E HEMATOLÓGICOS DA ANEMIA FALCIFORME
}

\author{
BIOCHEMICAL AND HEMATOLOGICAL ASPECTS OF SICKLE CELL HEMOGLOBIN
}

Laura de Souza Botelho Machadoํㅜ, Maria Júlia Pessanha Gonçalves ${ }^{1}$, Fernanda Lorena Matheus da Silva', Charbell Miguel Haddad Kury²

1 Acadêmicas de medicina da Faculdade de Medicina de Campos - FMC, Campos dos Goytacazes - RJ.

2 Professor titular da cadeira de Bioquímica, Faculdade de Medicina de Campos - FMC, Campos dos Goytacazes - RJ.

Seção de Revisão da Revista Científica da Faculdade de Medicina de Campos - Av. Alberto Torres, 217 - Centro, Campos dos Goytacazes - RJ, 28035-581

Endereço para correspondência: Laura de Souza Botelho Machado - Comendador José Francisco Sanguedo, 16 - ap 402, Campos dos Goytacazes - RJ - Ibotelhomachado@gmail.com - Campos dos Goytacazes - RJ - 2020

\section{RESUMO}

A anemia falciforme é a patologia hematológica hereditária mais comum no mundo, caracterizada pela alteração do aminoácido ácido glutâmico pela valina derivada de uma substituição da timina pela adenina no sexto códon no DNA do cromossomo 11. Essa substituição ocorre na cadeia beta da molécula de hemoglobina, tendo como consequência a formação de uma molécula anômala nomeada de hemoglobina S. A hemoglobina $S$ é originada na ausência de oxigenação, apresentando caráter insolúvel e, mediante a isso, ocorre a formação de fibras polimerizadas, resultando na produção das hemácias em foice. Este estudo objetiva a análise e descrição dos aspectos bioquímicos e hematológicos da anemia falciforme. Para tal, foi realizada uma revisão bibliográfica com busca por artigos científicos, livros e meio eletrônico, publicados entre o período de 2010 a 2020. Resultante desse processo, identificou-se a análise bioquímica e hematológica relacionadas ao fluxo sanguíneo lentificado, oclusão vascular e ao surgimento de lesões orgânicas que causam episódios inflamatórios, caracterizando as principais ocorrências da patologia.

Palavras-chaves: Anemia falciforme; hemoglobina; polimerização.

\begin{abstract}
Sickle cell anemia is the most common hereditary hematologic pathology in the world, characterized by the alteration of the amino acid glutamic acid by valine derived from a substitution of thymine for adenine without a sixth codon without DNA of chromosome 11. This substitution occurs in the beta chain of the hemoglobin molecule, resulting in the formation of an anomalous molecule named hemoglobin S. Hemoglobin $\mathrm{S}$ is originated in the absence of oxygenation, it has changed insoluble and, through this, polymerized fibers are formed, before the production of red blood cells in sickle. This study aims to analyze and describe the biochemical and hematological aspects of sickle cell anemia. To this end, a literature review was carried out with a search for scientific articles, books and electronic media, published between the period 2010 to 2020 . As a result of this process, the biochemical and hematological analysis related to slowed blood flow, vascular occlusion and the emergence of organic lesions that cause inflammatory episodes, characterizing them as the main occurrences of the pathology.

Keywords: Sicklecellhemoglobin; hemoglobin; polymerization.
\end{abstract}




\section{INTRODUÇÃO}

A anemia é uma condição caracterizada pela diminuição da concentração de hemoglobina $\mathrm{Hb}$ ) por unidade de sangue, abaixo da média considerada normal. As mutações na cadeia da hemoglobina, a eritropoese deficiente, a carência nutricional e a perda de células sanguíneas do meio intravascular estão relacionadas às causas da anemia (SANTOS e REIS, 2011). Desta forma, a anemia apresenta um falho processo para atender as demandas fisiológicas celulares, devido ao deficiente transporte de oxigênio. A anemia está relacionada à elevada morbidade e mortalidade em mulheres e crianças, associada a resultados não satisfatórios no parto; redução da produtividade nas atividades laborais no adulto e a redução do desenvolvimento cognitivo na criança (CHAPARRO e SUCHDEV, 2019).

De acordo com Herrick (1910, p. 1 apud MANDAL, 2020, p. 298) “o primeiro relato científico sobre a anemia falciforme foi descrito em 1910, em um estudante negro da escola profissional de Chicago, proveniente das Índias Ocidentais". Posteriormente, novos estudos tais como o de Linus Pauling e Vernon Ingram identificaram uma mutação na cadeia de hemoglobina. A etiologia da anemia falciforme é uma alteração genética na cadeia de globina da hemoglobina (COSTA et al., 2013). Existe uma substituição de uma das bases nitrogenadas, onde a timina é substituída pela adenina (GAT GTT) no sexto códon no DNA do cromossomo 11. A alteração da base nitrogenada irá codificar a produção do aminoácido valina ao invés do ácido glutâmico, modificando os aspectos físicoquímicos da hemoglobina (MANDAL et al., 2020).

A incidência da anemia falciforme prevalece em povos de diferentes regiões da África. Após o primeiro relato, os novos registros na literatura evidenciaram uma estreita relação entre populações negras e a doença falciforme. No Brasil, a maior prevalência da anemia falciforme ocorre nas Regiões Norte e Nordeste, devido ao alto grau de miscigenação. A anemia falciforme era desconhecida em algumas regiões como o norte da Europa, tendo como consequência as migrações, esta condição começou a ser frequente (BRASIL, 2018; COSTA et al., 2013).

O processo de substituição que acomete a cadeia beta de hemoglobina é responsável pela formação de uma molécula atípica, denominada hemoglobina S (HbS). A polimerização da HbS está relacionada com a fisiopatologia da anemia falciforme, uma vez que há a formação de hemácias de formato falcêmico, gerando distúrbios homeostáticos de alto impacto (MANDAL et al., 2020). A fase de polimerização é marcada pela ausência de oxigênio durante a passagem dos eritrócitos nos capilares sanguíneos, aumentando a permeabilidade da membrana aos cátions, o que culmina na ativação de vários sistemas de transporte, ocasionando o fluxo de líquido e desidratação eritrocitária. Os eritrócitos com hemoglobina polimerizada apresentam formato alterado com a conformação enrijecida, sucedendo em hemólise, processos oclusivos de pequenos capilares e ataques cardíacos manifestados como convulsões veno-oclusivas (ZUNIGA et al., 2018).

A eletroforese em gel e o método cromatográfico automatizado de troca de cátions são métodos que têm sido amplamente utilizados para a caracterização da HbS. Atualmente, o tratamento da anemia falciforme oferece um suporte clínico, abrangendo transfusões sanguíneas e controle das crises álgicas. No entanto, novos estudos orientam sobre o uso de determinados medicamentos que reduzem os níveis de hemoglobina S (MANDAL et al., 2020; TISDALE et al., 2020).

\section{OBJETIVOS}

Descrever os aspectos bioquímicos e hematológicos da anemia falciforme.

\section{MÉTODOS}

O estudo trata-se de uma revisão bibliográfica de ampla abordagem que combina dados da literatura que possibilita a análise e síntese de conhecimento científico, por meio do apuramento de pesquisas anteriores. Os descritores buscados foram "anemia", "hemoglobinopatia" e "anemia falciforme".

A revisão literária apresenta seis fases, as quais delinearam este estudo: 1) Identificação do tema; 2) Construção de análise; 3) Pesquisa na literatura; 4) Coleta de informações; 5) Análise criteriosa das pesquisas utilizadas; 6) Apresentação das considerações finais.

O levantamento bibliográfico é referido no período de 2010 até 2020 e sem limitação de idioma, através de pesquisas nas bases de dados de livros, 
meios eletrônicos: Pubmed, Scientific Library Online (Scielo) LILACS (Literatura Latino-Americana e do Caribe em Ciências da Saúde) e site relacionado à saúde (Ministério da Saúde).

\section{DESENVOLVIMENTO}

A hemoglobina é uma proteína tetramétrica localizada no interior dos eritrócitos. Cada molécula de hemoglobina é constituída por 4 cadeias heme e 4 cadeias de polipeptidios globina, que são compostas por 2 cadeias alfa e 2 cadeias não alfa ( $\beta$, $\gamma, \delta)$. A porção heme é formada por um anel de protoporfirina e um átomo de ferro ferroso, que permite a ligação com uma única molécula de oxigênio. Portanto, cada cadeia de globina envolve uma porção heme formando a hemoglobina. A afinidade do ferro ferroso com o oxigênio é determinada pela pressão parcial do oxigênio (pO2) dissolvido no sangue permitindo que a molécula de hemoglobina seja um transportador de oxigênio do pulmão para os tecidos (MANDAL et al., 2020; SANTOS e REIS, 2011).

As formas predominantes de hemoglobina no indivíduo normal após o nascimento são: hemoglobina $\mathrm{A}(\mathrm{HbA})$ formada por duas cadeias alfa e duas cadeias beta; hemoglobina A2 ( $\mathrm{HbA} 2$ ) constituída por duas cadeias alfa e duas cadeias delta; hemoglobina fetal ( $\mathrm{HbF}$ ) composta por duas cadeias alfa e duas cadeias gama. Em condições fisiológicas, aproximadamente $98 \%$ da hemoglobina circulante são $\mathrm{HbA}$, em torno de $2 \%$ da hemoglobina restante são na forma $A 2$, e abaixo de $1 \%$ representa a hemoglobina fetal, que possui a maior afinidade de oxigênio (SANTOS e REIS, 2011).

As hemoglobinopatias são patologias hematológicas genéticas que resultam na formação anormal de hemoglobina. A substituição, a deleção, ou inserção são mutações genéticas que podem acontecer nas cadeias polipeptídicas, levando assim a formação de variantes moleculares de hemoglobina. Essas alterações genéticas podem ser responsáveis por gerar disfunções referentes a forma celular e a propriedade de transporte de oxigênio. Atualmente, existem 1346 variantes de hemoglobina descobertas, sendo que 315 variantes são relatadas com distúrbios funcionais (MANDAL, et al., 2020; KEBER, et al., 2019). Segundo a Organização Mundial da Saúde (OMS), a doença falciforme é predominante dentre das hemoglobinopatias (BRASIL, 2018).

\section{ANEMIA FALCIFORME}

Em 1670, o fenótipo clínico da doença falciforme começou a ser observada em uma família africana. No entanto, o primeiro registro na literatura aconteceu, em 1910, pelo médico norteamericano James B. Herrick, que identificou a anemia falciforme em um indivíduo negro de origem caribenha. Em 1949, o químico Linus Pauling demonstrou a presença de uma alteração molecular na hemoglobina. Em 1957, o biólogo Vernon Ingram relatou o acometimento da cadeia beta, originando uma hemoglobina anômala denominada $\mathrm{S}$ ( $\mathrm{HbS}$ ) (MANDAL et al., 2020; COSTA et al., 2013).

A doença falciforme é uma condição genética autossômica recessiva (BRASIL, 2018; SUNDD, et al., 2019). A alteração molecular é representada no cromossomo 11 pela substituição de um único aminoácido no códon 6 do gene da cadeia beta, tendo a adenina (A) sendo substituída pela timina (T). A modificação converte um códon do ácido glutâmico (GAG) em um códon de valina (GTG) tendo como consequência a formação da HbS (SANTOS e REIS, 2011; PICCIN, et al., 2019). No entanto, o ácido glutâmico é hidrofílico e a valina é hidrofófica. Desta forma a $\mathrm{HbS}$ desoxigenada se torna insolúvel e ocorre a formação de fibras polimerizadas, resultando na formação das hemácias falcêmicas (PICCIN et al., 2019).

De modo geral, os genes variantes da hemoglobina originados das mutações são denominados de alelos. Na condição heterozigoto (AS), o indivíduo possui uma cópia de cada um dos alelos $\beta$ globina normal e alelo $\beta$ falciforme produzindo a hemoglobina adulta normal $(\mathrm{HbA})$ e a hemoglobina anômala ( $\mathrm{HbS}$ ) denominados como traço falciforme. Esse indivíduo não é acometido pelo fenótipo clínico da doença falciforme. No entanto, na condição homozigoto (SS) existem duas cópias dos alelos $\beta$ falciformes responsável pelo quadro sintomático (MANDAL et al., 2020; SANTOS e REIS, 2011).

\section{QUADRO CLÍNICO}

As manifestações clínicas são variáveis, alternando entre indivíduos assintomáticos, e sintomáticos que necessitam de frequentes internações hospitalares. A maioria dos pacientes homozigóticos (SS) apresentam o quadro clínico mais grave comparado aos pacientes heterozigóticos (AS). No entanto, a persistência da hemoglobina fetal 
atribui um melhor prognóstico, pois a $\mathrm{Hb}$ fetal possui maior afinidade com o oxigênio, diminuindo a polimerização (SANTOS e REIS, 2011).

Os portadores de anemia falciforme possuem períodos com ausência de sintomas equivalentes à fase estável da doença, que pode ser interrompida por manifestações agudas denominadas crises de falcização classificadas em crises vasoclusivas (álgicas), crises aplásticas, quadros hemolíticas e de sequestro esplênico (COSTA et al., 2013).

Os recém-nascidos portadores da doença falciforme possuem elevadas concentrações de $\mathrm{Hb}$ fetal, não apresentando quadro clinico relevante. Os primeiros sinais e sintomas surgem a partir dos seis meses de idade, devido a redução significativa da concentração de hemoglobina fetal (COSTA et al., 2013). Inicia-se um quadro de anemia hemolítica com icterícia e esplenomegalia (SANTOS e REIS, 2011).

A síndrome mão-pé ou dactilite falcêmica é um sinal característico nos primeiros dois anos de vida, caracterizada pela inflamação aguda que acomete os dedos das mãos e dos pés, em que ocorrem edema, calor, rubor e dor, caracterizando os sinais cardinais da inflamação. A inflamação pode ser limitada a falange ou metacarpo ou a todos os ossos na região. A dor é intensa podendo ser semelhante à das crises álgicas no adulto (SANTOS e REIS, 2011; KANAKIA et al., 2016).

As crises álgicas são uma das manifestações clínicas mais predominantes da doença falciforme, sendo que a incidência e prevalência variam de acordo com o sexo, idade, genótipo e alterações laboratoriais (KANAKIA et al., 2016).A dor é intensa, incapacitante e em alguns casos necessita de hospitalização para analgesia parenteral. A vasooclusão ocasiona o quadro doloroso. A falcização das hemácias é responsável por micro-obstruções vasculares causando isquemia nos tecidos, resultando em uma resposta inflamatória aguda (COSTA et al., 2013). Em geral, as crises dolorosas atingem a região lombar, abdome, tórax e articulação acometendo com maior frequência as mãos e os pés (KANAKIA et al., 2016). As crises álgicas são deflagradas por infecção, desidratação, atividade física, hipóxia, alteração brusca de temperatura e menstruação. No entanto, diante de um paciente com crise, a investigação de infecção é bastante relevante (SANTOS e REIS, 2011).
Os episódios de vaso-oclusão podem afetar vários órgãos. $\mathrm{O}$ acúmulo de eritrócitos falcizados em vasos sanguíneos resultará na hipóxia, tendo como consequência a lesão tecidual. Os órgãos que apresentam uma circulação sanguínea lenta, com menor tensão de oxigênio, baixo pH (por exemplo: rim, fígado e medula óssea) ou limitada suplementação de sangue arterial (por exemplo: retina e cabeça do fêmur) apresentam maior risco de ter oclusão dos vasos sanguíneos (SANTOS e REIS, 2011; COSTA et al., 2013).

As complicações renais são secundárias aos microinfartos renais, como a hematúria, proteinúria, hipertensão, necrose papilar, isquemia parenquimatosa que culmina em glomeruloesclerose segmentar e insuficiência renal crônica. Em relação à retina, os quadros clínicos são a retinopatia proliferativa, oclusão da artéria retiniana, descolamento da retina, hemorragias podendo ocasionar a cegueira. Já as manifestações ósseas ocorrem devido a necrose óssea isquêmica da cabeça do fêmur ou úmero, favorecendo o surgimento da osteomielite por falha de perfusão. A Salmonella e Staphylococcus aureus são os agentes etiológicos predominantes da osteomielite na anemia falciforme. O priaprismo é uma ereção sustentada, involuntária e dolorosa, sendo também uma consequência da vaso-oclusão que oclui a drenagem venosa dos corpos cavernosos do pênis. É considerado urgência médica e requer uma avaliação urológica (SANTOS e REIS, 2011).

$\mathrm{Na}$ crise aplástica, ocorre uma redução significativa e transitória da proliferação medular, resultando na diminuição da concentração de hemoglobina acompanhada de níveis de reticulócitos reduzidos, determinando uma insuficiência transitória da eritropoese. Esta condição acontece, porque na anemia falciforme há um decréscimo na meia vida das hemácias para a média de 17 dias. Geralmente, a crise aplástica é incitada pela infecção por parvovírus B19, sendo os demais casos por Salmonella, Streptococcus ou vírus Epstein-Barr (COSTA et al., 2013).

A crise hemolítica é determinada pelo acentuado aumento na taxa de hemólise com reticulocitose, diante de quadros infecciosos por Mycoplasma, deficiência de G6PD ou esferocitose hereditária. As manifestações clínicas compreendem uma marcante icterícia e agravamento da anemia (COSTA et al., 2013). 
O sequestro esplênico é definido pela redução nos níveis basais de hemoglobina de pelo menos $2 \mathrm{~g} / \mathrm{dL}$, plaquetopenia, reticulocitose e esplenomegalia. Esta crise ocasiona um quadro agudo definida pelo acúmulo de hemácias no baço podendo resultar no choque hipovolêmico que se manifesta através dos sintomas de hipovolemia como taquicardia, palidez, taquipneia, hipotensão e choque. Ocorre normalmente em crianças nos primeiros cinco anos de vida, sendo causa de grande mortalidade, quando o tratamento não é imediato (KANAKIA et al., 2016).

\section{CARACTERIZAÇÃO DE HBS}

A eletroforese em gel e o método cromatográfico automatizado de troca de cátions são técnicas utilizadas como métodos diagnósticos para identificação da Hbs. A eletroforese em gel alcalino tem como base a redução líquida em carga negativa de moléculas de $\mathrm{Hbs}$, comparada com os tetrâmeros de HbA. Ocasionada pela troca do ácido glutâmico negativamente carregado por uma valina neutra, a migração da $\mathrm{HbA}$ é mais acelerada do que a $\mathrm{HbS}$. Todavia, pode haver uma migração adjunta da $\mathrm{HbS}$ com outras variações de hemoglobina, entre elas $H b D, H b Q$, ocasionando em uma dualidade diagnóstica, comprometendo a eficácia da análise (MANDAL et al., 2020).

Já no método cromatográfico a base de troca catiônica, utilizam-se diversas concentrações de tampões de fosfato como fase móvel e uma resina de troca catiônica como fase estacionária. Moléculas variantes de hemoglobina tetramérica são separadas a partir de sua interação com as fases. A HbS possui uma natureza mais catiônica quando comparada com a $\mathrm{HbA}$, logo flui mais devagar na técnica de separação cromatográfica de troca catiônica (MANDAL et al., 2020).

\section{EQUILÍBRIO DE LIGAÇÃO DE OXIGÊNIO DE HBS}

$A$ atividade funcional da hemoglobina é mensurada através do equilíbrio de ligação de oxigênio, onde a fração de hemoglobina saturada é determinada pela pressão parcial de oxigênio, em que $50 \%$ da hemoglobina estão saturados (P50) (MANDAL et al.,2020). Em geral, a afinidade do oxigênio pela hemoglobina depende do $\mathrm{pH}$, da concentração de CO2, 2,3-difosfoglicerato (2,3DPG) e temperatura. A P50 é normal em $27 \mathrm{mmHg}$ de $\mathrm{O} 2$, em $\mathrm{pH}$ de 7,4 e temperatura de 37,4 으 (SANTOS e REIS, 2011).

Nas variantes de hemoglobina, o aumento da afinidade do oxigênio demonstra uma redução no p50, enquanto a redução na afinidade do oxigênio indica o aumento no p50. Na doença falciforme, ocorre uma diminuição da afinidade do oxigênio pela hemoglobina. Esta condição está relacionada ao aumento da concentração intracelular de 2,3-DPG, sendo um mecanismo compensatório com o objetivo de diminuir a afinidade do oxigênio pela hemoglobina, facilitando a liberação para os tecidos. Nos pacientes com anemia falciforme, a concentração de 2,3-DPG e p50 variam com frequência (MANDAL et al.,2020).

\section{POLIMERIZAÇÃO DE HBS}

A polimerização da hemoglobina $S$ é um evento essencial relacionado a fisiopatogenia da doença falciforme, tendo como consequência a alteração da morfologia do eritrócito gerando o caráter falciforme. Esta condição acontece somente na forma desoxigenada da HbS. Após a reoxigenação, a polimerização se desfaz e a hemácia retorna a sua forma bicôncava. Na presença de oxigênio a polimerização é um processo reversível (SUNDD et al., 2019; COSTA et al., 2013).

No entanto, a frequente polimerização e despolimerização provocam lesões de membrana nas hemácias, fazendo com que a rigidez e a configuração falciforme perdurem mesmo com o processo de reoxigenação. Deste modo, esses eritrócitos são denominados células irreversivelmente falcizadas, pois apresentam permanentemente o formato falcêmico (SANTOS e REIS, 2011; SUNDD et al., 2019).

As lesões progressivas na membrana causam rigidez e deformidades identificadas pelo sistema reticulo-endotelial ocasionando a destruição dessas células pelos macrófagos. As hemácias falcizadas são responsáveis pela hemólise crônica contribuindo significativamente para a anemia hemolítica, já que essas hemácias alteradas apresentam meia-vida abaixo de 120 dias (MANDAL et al., 2020; SANTOS e REIS, 2011).

$\mathrm{Na}$ anemia falciforme, os eritrócitos anormais são responsáveis pela lentificação do fluxo sanguíneo, oclusão vascular e lesões orgânicas causando uma inflamação, que representam os principais fenômenos patológicos (MANDAL et al., 2020). 
A desoxigenação intraeritrocítica de $\mathrm{HbS}$ em tecidos com elevado consumo de oxigênio gera a exteriorização de sítios hidrofóbicos em tetrâmeros de HbS desoxigenados.Desta forma, as cadeias de $\beta$ S-globina em diferentes tetrâmeros de $\mathrm{HbS}$ desoxigenados acoplam-se para mascarar os sítios hidrofóbicos, culminando na nucleação de um polímero de HbS. Esses polímeros de HbS ampliamse de rápida forma a fim de constituir fibras longas que impulsionam a rigidez celular e promovem uma distorção da membrana eritrocitária, ocasionando a falcização eritrocitária, falha energética celular e estresse, desidratação e hemólise prematura (MANDAL et al., 2020).

\section{INIBIÇÃO NA POLIMERIZAÇÃO DE HBS}

A polimerização de HbS impacta diretamente nos aspectos fisiolopatológicos da doença falciforme. A cinética da polimerização tem um tempo de atraso, um período de latência necessário para que ocorra a agregação de aproximadamente 15 a 30 tetrâmeros de moléculas de hemoglobinas, resultando na formação de um único núcleo na etapa de polimerização das fibras individuais. Sabe-se que o evento da polimerização é inibido quando o tempo de atraso associado à nucleação de tetrâmeros é excedente ao tempo de passagem de hemácias no processo de desoxigenação de $\mathrm{HbS}$ através da circulação capilar periférica para os alvéolos pulmonares, na reoxigenação. Em virtude disso, a estabilização da forma oxigenada da HbS é um fator limitante no tratamento medicamentoso da doença, uma vez que a forma oxi não é polimeralizada. Portanto, é de suma importância a compreensão molecular das distintas formas de $\mathrm{HbS}$ em termos de sua dinâmica conformacional (MANDAL et al.,2020).

\section{ALTERAÇÕES NA MEMBRANA ERITROCITÁRIA}

A hidratação celular é mantida por numerosos canais de transporte de íons localizados na membrana dos eritrócitos. Dentre eles, uns dos mais relevantes a serem citados são o canal de Gardos e o sistema de co-transporte $\mathrm{K}-\mathrm{Cl}$. Ao ser ativado, este sistema de cotransporte ocasiona um processo de desidratação mediado pela saída de K+ e $\mathrm{Cl}-$ da célula, subsequente a saída de água. Esse mecanismo está potencializado nas células dos indivíduos com anemia falciforme, resultando em um acréscimo da concentração intracelular de HbS, suscetibilizando a sua polimerização. Já o canal de Gardos é responsável pelo efluxo de potássio, sendo sua ativação promovida pelo aumento da concentração de cálcio intracelular resultante do processo de desoxigenação e do caráter falcêmico eritrocitário. (PICCIN et al., 2019) Assim como acontece na dinâmica do sistema $\mathrm{K}-\mathrm{Cl}$, o efluxo de potássio subsequente a saída de água gera um quadro de desidratação celular e um acréscimo da concentração de HbS. A cinética do canal de Gardos é alterada também pela endotelina, vasoativo acrescido nos quadros falcêmicos, prostaglandina E2 e outras citocinas que desidratam e polimerizam a HbS (CONRAN e BELCHER, 2018).

Além disso, a mudança do padrão discóide eritrocitário pelo falcêmico altera o funcionamento da bomba $\mathrm{Na}+\mathrm{K}$, ocasionando efluxo de potássio e água, aumentando a densidade das hemácias e propiciando a extensão de polímeros de HbS. Há também o processo do aumento da concentração intracelular de $\mathrm{Ca}+2$ pela falência da bomba de Ca2+/ATPase e da concentração de hemoglobina corpuscular média da desoxi-HbS. Ambos os processos descritos reduzem a permeabilidade celular (STYPULKOWSKI e MANFREDINI, 2010).

As membranas celulares são alteradas pela reestruturação protéica do citoesqueleto (band-3, anquirina e espectrina-actina), redução glicoprotéica, externalização da fosfatilsiderina (FS), geração de radicais livres e agilidade do processo apoptótico gerado do acréscimo da ação do cálcio a nível citosólico (STYPULKOWSKI e MANFREDINI, 2010). Injúrias a proteína band-3 podem acarretar em processos falcêmicos, visto que esta é fundamental para assegurar a integridade citoesquelética, a passagem de ânions pelas membranas, o ajuste do volume eritrocitário e a remoção de CO2 (PICCIN et al., 2019).

\section{DISFUNÇÃO ENDOTELIAL - MOLÉCULAS DE ADESÃO E VASO-OCLUSÃO}

Os glóbulos vermelhos com quantidade elevada de HbS têm seu formato alterado sendo cronicamente propensos às lesões de membrana com hemólise, a nível extra e intravascular, ocasionando um déficit de óxido nítrico disponível e acréscimo do tônus vascular. 0 padrão superficial anômalo é responsável pelo crescimento da aderência e lesão ao endotélio vascular, evento que culmina em vaso-oclusão e a vasculopatia 
proliferativa contemplando a participação de citocinas, proteínas da coagulação, células de músculo liso, fatores de crescimento, plaquetas e leucócitos (SUNDD et al., 2019).

Diversos fatores são responsáveis por propiciar o evento da oclusão dos capilares na anemia falciforme, sendo este primordialmente proporcional a formação de polímeros de $\mathrm{HbS}$. Isso gera uma desaceleração da passagem das células falciformes nos capilares e favorece a adesão destes no endotélio. Sendo assim, a vaso-oclusão inicia-se com a aderência vascular dos eritrócitos falcizados e, posteriormente, há uma retenção de células de formato mais preservado. A ligação desses eritrócitos anômalos às células endoteliais é auxiliada também pelas proteínas plasmáticas, a exemplo do fibrinogênio, fator de Von Willebrand, fibronectina e trombospondina. A estase venosa desencadeada é responsável por levar ao quadro de hipóxia a nível tecidual, culminando na conversão de mais $\mathrm{HbS}$ em desoxi-HbS. Com isso, há uma exacerbação da descompensação homeostática, gerando lesões nos tecidos, visto que a perfusão capilar está comprometida (STYPULKOWSKI e MANFREDINI, 2010; PICCIN, et al., 2019).

O excesso de proteínas inflamatórias a nível plasmático é responsável por aumentar a expressão das moléculas de adesão vascular VCAM-1, as moléculas de adesão intercelular ICAM-1 e o fator tecidual. Este último está inserido na superfície membranosa celular como proteína integral nos indivíduos falcêmicos, no entanto isso não ocorre em condições fisiológicas nas células endoteliais e nos leucócitos. Essa alta expressão de FT das células endoteliais leva ativação do processo da cascata de coagulação por promover a interação deste com o fator VIIa, ativando serinoproteases, incluindo fatores IX, X, XII e trombina. Os eritrócitos falcizados e leucócitos possuem receptores de adesão que interagem com as proteínas E- selectina, P-selectina, fibronectina, laminina, integrina, que são proteínas de adesão, ocasionando o processo vasoclusivo (SUNDD, et al., 2019; PICCIN, et al., 2019).

Os eritrócitos falcêmicos têm a assimetria de fosfolipídios de membrana interna alterada, ocorrendo tanto em reticulócitos quanto nos eritrócitos maduros na corrente sanguínea, exteriorizando a fosfatilsiderina (FS). Este processo é devido às sucessivas falcizações e desfalcizações cíclicas. Com a externalização da FS, proteínas da coagulação e plaquetas são ativadas, há uma expressão aumentada de moléculas endoteliais vasculares de adesão e anemia, isso porque essas células têm uma meia vida diminuída, pois são identificadas e eliminadas pelo processo fagocitário (STYPULKOWSKI e MANFREDINI, 2010).

$O$ estado de hipercoagulabilidade nos indivíduos falcizados pode ser explicado pela cronicidade da ativação plaquetária. Tal fato relaciona-se com uma grande quantidade de megacariócitos na circulação sanguínea e uma exacerbação da concentração de agonistas das plaquetas como adrenalina, adenosina difosfato (ADP) e trombina (STYPULKOWSKI e MANFREDINI, 2010).

Pacientes com anemia falciforme tendem a apresentar disfunção endotelial pela diminuição da biodisponibilidade de óxido nítrico. O óxido nítrico é produzido pelas enzimas óxido nítrico sintetases, localizadas vastamente desde células endoteliais vasculares até células neuronais. O NO é um cofator da enzima guanilato-ciclase que converte trifosfato de guanosina (GTP) em monofostato de guanina cíclica (cGMP), promovendo o relaxamento dos músculos lisos vasculares e um efeito vasodilatador. Ademais, exerce também um importante papel homeostático, pois inibe a expressão de moléculas de adesão e age na inibição de plaquetas no endotélio nas várias etapas do processo, desde adesão a agregação, interrompendo a formação trombótica. A oxi-hemoglobina (oxi-Hb) das hemácias são as responsáveis pela inativação do óxido nítrico na corrente sanguínea. A membrana eritrocitária e proteínas citoesqueléticas também constituem fatores para a difusão limitada (STYPULKOWSKI e MANFREDINI, 2010).

Durantes as crises falciformes, há uma elevação da xantina oxidase hepática (XO). Essa promove uma ligação com as células do endotélio, comprometendo a função vascular através da instauração de um ambiente oxidativo, catalisando o óxido nítrico, diminuindo sua biodisponibilidade (PICCIN et al., 2019).

No entanto, o NO é capaz de interagir com o grupamento heme da desoxihemoglobina, gerando a formação de substratos que atuam como fontes bioativas de NO. Através disso, a $\mathrm{Hb}$ atua antagonicamente, tanto inativando o NO, como também promovendo o transporte do gás na corrente sanguínea. Como mecanismos de proteção 
do consumo de NO pela hemoglobina, temos o fluxo sanguíneo laminar e a delimitação da hemoglobina dentro dos eritrócitos. A quantidade de NO em pacientes falcêmicos é limitada, pois a oxihemoglobina livre plasmática gerada pela hemólise intravascular transforma NO em nitrato inativo. Além disso, há liberação de arginase que destrói L-arginina, substrato para a produção de NO, reduzindo a biodisponibilidade de NO. Assim, a hemólise intravascular culmina em um quadro de impedimento da vasodilatação dependente de NO e de antiagregação plaquetária (STYPULKOWSKI e MANFREDINI, 2010).

\section{DIAGNÓSTICO}

O diagnóstico para anemia falciforme não é complexo, visto que a hemoglobina é encontrada em alta concentração no sangue e variados métodos são capazes de identificar $\mathrm{HbS}$ e hemoglobinas variantes. A eletroforese consistindo na separação de hemoglobinas normais das anormais é a técnica de maior utilização, utilizando gel alcalino padrão, focagem isoelétrica, eletroforese capilar ou cromatografia líquida de alto desempenho (WILLIAMS e THEIN, 2018). No entanto, o hemograma nem sempre é característico, podendo ser observado quadros de anemia normocrômica normocítica, com ou sem reticulocitose, logo a avaliação clínica é primordial para o diagnóstico. Os testes químicos e de solubilidade que caracterizam a presença de $\mathrm{HbS}$ são suscetíveis a resultados errôneos e sua utilização isolada não é indicada para fechar o diagnóstico. Outros métodos mais recentes, como testes baseados em DNA ou em anticorpos possibilitam diagnósticos precisos e vem sido utilizados na prática clínica (ZUNIGA et al., 2018).

\section{TRATAMENTO}

\section{Hidroxiuréia}

A hidroxiuréia (HU) tem se apresentado como um importante redutor das crises falciformes, sendo capaz de promover um impacto positivo no prognóstico dos pacientes falcêmicos. Seu mecanismo de ação ainda é desconhecido, todavia, sabe-se que ela é responsável por aumentar a produção de hemoglobina fetal. Duas cadeias de globina $\alpha$ e duas cadeias de globina $\gamma$ compõem a hemoglobina fetal e a sequência de aminoácidos desta é diferente da HbS, sendo assim a hemoglobina fetal não polimeriza com a $\mathrm{HbS}$.
Mesmo mediante às altas concentrações desta última, a HU é capaz de diminuir a falcização, possibilitando que mais células escapem dos capilares periféricos antes que ocorra o adoecimento, consequentemente, reduz os eventos vaso-oclusivos e hemolíticos (TISDALE et al., 2020).

\section{Voxelotor}

O voxelotor foi aprovado pela Food and Drug Administration (FDA) apenas em 2019, sendo considerada uma droga recente. Esta é um inibidor da cadeia alfa da hemoglobina, modulando a afinidade da hemoglobina pelo oxigênio. Ao promover a estabilização dos eritrócitos na conformação oxigenada, há o bloqueio da polimerização da hemoglobina, evitando a falcização e destruição eritrocitária. Tem-se sugerido que as reduções da falcização e o prolongamento da meiavida dos glóbulos vermelhos são responsáveis por diminuir a viscosidade sanguínea, hemólise e, subsequentemente, o quadro anêmico (HERITY et al., 2020).

\section{Crizanlizumabe}

O crizanlizumabe é um anticorpo monoclonal, aprovado em 2019 pela FDA, com objetivo de bloquear a P-selectina, molécula de adesão expressa pelos eritrócitos (TISDALE et al.,2020). O tempo de trânsito dos eritrócitos pelos capilares teciduais em comparação ao tempo de atraso da polimerização da HbS é um fator determinante no acometimento da anemia falciforme. A partir disso, tem-se que o acometimento em vasos de pequeno calibre pode ser diminuído com o aumento do tempo de atraso e também pela redução da adesão dos eritrócitos ao endotélio vascular, diminuindo o tempo de trânsito.

\section{Glutamina}

A glutamina é um importante aminoácido que estimula da produção de arginina, nicotinamida (NAD) e glutationa (GSH), moléculas envolvidas no mecanismo de proteção de injúrias vasculares oxidativos, reduzindo os episódios de dor aguda e internações (PICCIN, et al., 2019; PIEL, et al., 2017).

\section{Transfusões}

A terapia consiste em receber eritrócitos de doadores que possuem uma concentração normal de $\mathrm{HbA}$. O tratamento é baseado na diminuição de 
HbS para um valor $30 \%$ abaixo da concentração de hemoglobina total. (ZUNIGA et al., 2018). Transfusões realizadas a longo prazo visam a supressão da produção eritrocitária a nível medular em indivíduos com recaídas de síndromes pulmonares agudas, não responsivos à utilização de hidroxiureia, objetivando a prevenção de acidentes vasculares cerebrais ou em casos de danos orgânicos progressivos (PINTO et al., 2019).

\section{Transplante de células progenitoras hematopoiéticas}

É o único método de tratamento curativo utilizado, no entanto sua utilização é feita somente em casos específicos, como a crise dolorosa intensa afetando a qualidade de vida e casos de anemia grave (ZUNIGA et al., 2018).

\section{CONSIDERAÇÕES FINAIS}

A anemia falciforme é uma condição clínica de alta relevância que apresenta múltiplas condições envolvidas e sua compreensão ainda é limitada. A elucidação dos aspectos da bioquímica e hematologia da anemia falciforme é primordial, uma vez que se pode constatar que as alterações nas membranas dos eritrócitos levam à desidratação celular e às reestruturações ocorridas a nível de citoesqueleto, possuindo íntima relação com o mecanismo de falcização. Ademais, a formação de polímeros e a consequente diminuição do trânsito de eritrócitos são responsáveis pela geração de processos hemolíticos e vaso-oclusivos, que alteram significativamente a qualidade de vida do paciente.

\section{REFERÊNCIAS}

BRASIL (2018). Ministério da Saúde. Secretaria de Atenção à Saúde. Secretaria De Ciência, Tecnologia e Insumos Estratégicos. Portaria Conjunta № 05.Brasília (DF), 2018.

CHAPARRO, Camila M. SUCHDEV, Parminder S.Anemia epidemiology, pathophysiology, andetiology in low-andmiddle-income countries. Annalsof The New York AcademyofSciences. V. 1450, N 15-31. doi: 10.1111/nyas.14092.

CONRAN, Nicola. BELCHER, John D. Inflammation in SickleCellDisease. ClinHemorheolMicrocirc. 2018;68(23):263-299. doi: 10.3233/CH-189012.

COSTA, Fernando F. CONRAN, Nicola. FERTIN, Kleber Y. Anemia Falciforme. In:ZAGO, Marco A. Falcão, Roberto P. PASQUINI, Ricardo, editores. Tratado de Hematologia.1a ed. São Paulo: Atheneu, 2013. p. 205-223

HERITY, Leah B. et al.Voxelotor: A Novel Treatment for SickleCellDisease. Ann Pharmacother. 2021

Feb;55(2):240-245. doi: 10.1177/1060028020943059.

KANAKIA, Swati. et al. SickleCell Anemia in Children.In: LOKESHWAR, M. SHAH, N. AGARWAL, B. (editores) TextbookofPediatricHematologyand Hemato-Oncology. 1a ed. New Delhi: Jaypee Brothers Medical Publishers, 2016. p. 190-203

KEBER, Barbara. et al. HematologicConditions: Common Hemoglobinopathies. FP Essent. 2019 Oct;485:24-31. PMID: 31613565.

MANDAL, Amit K. MITRA, Amrita. DAS, Rajdeep. SickleCellHemoglobin.SubcellBiochem. 2020;94:297-322. doi: 10.1007/978-3-030-41769-7_12.

PICCIN, Andrea. et al. Insight intothecomplexpathophysiologyofsicklecellanaemiaandpossibletreatment.Eur J Haematol. 2019 Apr;102(4):319-330. doi: 10.1111/ejh.13212.

PIEL, Frédéric B. STEINBERG, Martin H. REES, David C. SickleCellDisease. NewEnglandJournalof Medicine. 2017,Apr 20;376(16):1561-1573. doi: 10.1056/NEJMra1510865.

PINTO, Valéria M. et al.Sicklecelldisease: a review for theinternist.InternalEmergency Medicine. 2019 Oct;14(7):1051-1064. doi: 10.1007/s11739-019-02160-x.

SANTOS, Fernanda.Anemias pós-hemorrágicas e hiperploriferativas.In:SANTOS, Fernanda M. REIS, Marcos L.Principais Temas em Hematologia. 1a ed. Vol. 7. São Paulo: Medcel; 2011.

SUNDD, Prithu. GLADWIN, Mark T. NOVELLI, Enrico M. PathophysiologyofSickleCellDisease. Annual Review ofPathology: MechanismsofDisease Vol. 14, 2019. P. 263-292. 
STYPULKOWSKI, Jaíne B.MANFREDINI, Vanusa. Alterações hemostáticas em pacientes com doença falciforme. Rev. Bras. Hematol. Hemoter. [online]. 2010, vol.32, n.1, pp.56-62. EpubFeb 26, 2010. ISSN 1516-8484. https://doi.org/10.1590/S1516-84842010005000001.

TISDALE, John F. THEIN, Swee L. EATON, William A. Treatingsicklecell anemia. Science. 2020 Mar 13;367(6483):1198-1199. doi: 10.1126/science.aba3827. PMID: 32165573.

WILLIAMS, Thomas N. THEIN, Swee L. SickleCell Anemia and Its Phenotypes.Annual Review ofGenomicsandHumanGenetics. Vol. 19: p. 113-147. doi:10.1146/annurev-genom-083117-021320 ZÚÑIGA, Pamela C. et al. Enfermedad de células falciformes: Un diagnóstico para tener presente [Sicklecelldisease: A diagnosistokeep in mind]. RevChilPediatr. 2018 Aug;89(4):525-529. Spanish. doi: $10.4067 /$ S0370-41062018005000604. 